\section{CONVENTIONAL STARS}

\section{Stellar Astronomy}

Edited by Hong-Yee Chiu, Robert L. Warasila and John L. Remo. (Proceedings of the Summer Institute for Observational Astronomy, held at the State University of Now York at Stony Brook, Summer 1967.) Vol. 1: Pp. xiv +374 . Vol. 2: Pp. xiv +354 . (Gordon and Breach: New York and London, August 1969.) 295s each vol. ; $412 s 6 d$ the set.

Authougr in the past year or two astronomy has tended to be identified with the breathless pursuit of quasars, pulsars and microwave sources, the study of conventional stars still presents a great variety of challenging problems, among ther the evolution of close binaries, the whitedwarf and related evolutionary stages of single stars, the distribution of elements, the shedding of mass and angular momentum and the interpretation of new unexpected results in the ultraviolet and infrared.

This book gives an extended bird's-eye view over these and other problems with the emphasis largely on observation, although theory is by no means neglected. Various basic techniques (astrometry, photometry, spectroscopy and automation) are covered in the first and final sections, while the others deal with stellar classification, the iriterpretation of spectral lines, stellar rotation, angular momentum and binaries, white dwarfs and magnetic stars, the theory of stellar evolution and ultraviolet and infrared astronomy.

Many of the contributions are particularly noteworthy either because they contain interesting information not readily accessible elsewhere or for their clarity. In the first volume, for example, D. L. Crawford gives an unusually thorough discussion of photometric reduction procedures, W. P. Bidolman explains very clearly what is involved in spectral classification and the different types of peculiar spectrak, and B. Strömgren and T. Kelsall give extensive data on the calibration and achievements of four-colour photometry. In the last part of the first volume and the first part of the second, R. P. Kraft and Su-Shu Huang provide a most interesting account of angular momentum problems in single stars, close binaries and hypothctical planetary systems. The second volume also contains excellent discussions of white dwarfs by W. J. Luyten and J. L. Greenstoin, a fine summary by I. Ibon of the theory of stellar evolution from main sequonce to red giant and very valuable and stimulating progross reports on infrared and ultreviolet observations of stars by J. C. Morton, E. B. Jenkins, A. Poveda and N. J. Woolf. S. P. Maran rounds off the book with a fascinating and forward-looking account of autornated teloscopos and associated instrumentation.

These articles, together with others too numorous to be listed here, provide an excellent survey of many aspects of stcollar astronomy. Other important aspects, such as variable stars, have not beon included and there is no unifying thread to tell the beginner what the subject is all about. Consequently, and particularly in view of the high price of the book, one can hardly rocommend it for purchase by individual graduate students, but it will be an essential acquisition for every astronomy library.

B. E. J. PAGEL

\section{TRIBUTE TO A CHEMIST}

\section{Coordination Chemistry}

Papers Presented in Honor of Professor John C. Railar, jun. Edited by Stanley Kirschner. (Proceedings of the John C. Bailar jun. Symposium on Coordination Chemistry hold at Illinois, June 22-25, 1969.) Pp. xxvi + 331. (Plenum: Now York, 1969.) n.p.

JoHN C. BAILAR, jun., is one of the father figures of American coordination chemistry, and the influences of his own interests in this field have undoubtedly, through his research students and their research students, had a great effect in determining the direction of research in this field in the United States. Many of the most respected practitioners in the art received their first research experience with Bailar ( $84 \mathrm{PhD}$ students, 18 postdoctoral fellows to date) and have gone on in their turn to make a definite mark in coordination chemistry. If one were to try to define a Bailar man, he would be a chemist who does a great deal of his synthesis in hydroxylic solvents, who is not afraid to use fairly exotic organic ligands to achieve complexation, who is interested in the geometry of the ligand about the metal, and above all is not afraid that his complexes may be used (nearly a quarter of the contributions in this book are from industry or from research centres outside universities).

In June 1969, a symposium was held to celebrate Professor Bailar's 65th birthday, and twenty-two of the papers presented at the symposium have been collected together in the book under review. I have frequently found that books which present papers given at symposia contain unrelated material which saw print merely to provide a ticket to enable the author to attend the meeting. In this case, there is a unity about the papers which exhances the chemistry and certainly brings out Bailar's influence. Some of the papers report now, previously unpublished work; some are short reviews of specialist topics - they cover many aspects of coordination chemistry, but are all interesting and readable. The book is very well produced and edited, although it is a minor irritation that many different units are used to describe the same physical effects.

This book is good reading for chemists who wish to discern a logical line linking various aspects of chemistry. It is to be hoped that those authors who have made contributions of new research to this volume will resist the tomptation to republish elsewhere, for in this way those who read the papers here may notice the other papers and consider the deoper aspects of this resoarch. The volume is a very fitting tribute to a great and influential chemist.

D. W. A. Sharp

\section{ANALYTICAL CHEMISTRY}

\section{Complexometric Titrations}

By Gerold Schwarzenbach and Hermann Flaschka. Second English edition translated and revised in collaboration with the authors by H. M. N. H. Irving. Pp. xxii + 490. (Methuen: London, August 1969.) $90 \mathrm{~s}$.

Photometric Methods of Analysis

By A. B. Calder. Pp. $312+21$ plates. (Hilger: London, July 1969.) $104 s$.

THE original edition of Schwarzenbach's Die Komplexo. melrische Titration, which appeared in 1955 , was received with enthusiasm as the definitive textbook on this new technique of titrating metal ions in aqueous solutions as if they were acids. The new technique completely revolutionized the entire area of inorganic macro-analysis because it presented, for the first time, a perfectly general mothod for the titration of metal ions where proviously gravimetric methods had reigned supreme. The beneficial effects which arose from the discovery of the complexones as metal ion titrants were enormous, and this area of investigation occupied some of the best brains in analytical chemistry from approximately 1950 to 1960 . It is now as difficult to imagine inorganic analysis without complexometric titration as it is to imagine organic chemistry without chromatography in its various guises. In 1957, Professor Harry Irving translatod the first English edition and in 1969 we now have the same translator presenting the second English edition from the fifth German version of 1965 , which was written in conjunction with Professor 